\title{
Exploration and Research of Practical Teaching System Based on Ability Training
}

\author{
Huiting $\mathrm{Wu}$ \\ College of Information Engineering \\ Chutian College Huazhong Agricultural University \\ Wuhan, China \\ ccnuwht@163.com
}

\author{
Yi Wang \\ College of Information Engineering \\ Chutian College Huazhong Agricultural University \\ Wuhan, China \\ wy_hb@mail.hzau.edu.cn
}

\begin{abstract}
Applied talents are trained who has reasonable knowledge structure and ability to analyze and solve actual problem. We propose a practice teaching system based on ability training which used the ability training as the core. And a lot of research and practice have to be done according to curriculum system, teaching content, teaching methods, teaching methods and assessment methods. From the knowledge oriented to ability oriented, it cultivates students' autonomous learning ability and improves the students' practical ability for social demand.
\end{abstract}

Keywords- ability; practice teaching; training goal; reform

\section{INTRODUCTION}

There is contradiction between employment rate of graduates and social demand in the computer specialty of independent college. The main reason is that there are following problems in the computer training. In the computer specialty of independent college, the training of talents is greatly paid attention to [1]. Most research is done in the training of the ability of students. But these researches are mainly focused on the construction of curriculum system, such as increasing more application oriented curriculum and the proportion of practice courses. There is not too much research in the teaching content, teaching methods and assessment methods according to the characteristics of independent colleges.

Applied talents are trained who has reasonable knowledge structure and ability to analyze and solve actual problem, such as design ability, using software capability, information extraction ability, product selection ability, allocation of environmental capacity and support ability. Cultivation mode of college can not completely paraphrase in the independent college. The application of training students to analyze and solve the actual problem ability must be reflected in the implementation of curriculum teaching. how to comprehensive ability training system should be researched.

Based on the analysis of above, we propose a teaching system based on ability training which used the ability training as the core. And a lot of research and practice have to be done according to curriculum system, teaching content, teaching methods, teaching methods and assessment methods.

\section{MODE OF TRAINING TALENTS BASED ON ABILITY TRAINING}

The computer education has become an important part of the education in schools and educational institutions in china. The traditional mode of education is the mode of examoriented education which is evolved from imperial examination system. Its education idea is regarded as subject oriented theory, which regards discipline theory as the target content of personnel training. Teaching theories is its main task. And it uses the degree of reception theory knowledge to measure quality of talent cultivation and the effect of teaching. In the Higher Education model of traditional concept guidance, the curriculum design is based on the theoretical system of the discipline. The main teaching method is cramming education, and the assessment uses a single closed book examination. This mode of education is very common in the independent colleges, and students are lack of strong practical ability [2]. What's more, few engineering and computer graduates are as good as their qualifications suggest. The paper will target at the training mode of applied talents in computer specialty based on ability oriented, explore the reform of practice teaching methods, teaching means and assessment methods based on ability training.

\section{A. Determine the training target system of professional practice ability}

Any professional will set up personnel training goal. However, the target is not top-level design in general. Personnel training target is less clear in what ability should be enhanced. It makes disconnect between training target and the talent training scheme and the professional teaching lack a main line [3]. Training target system of the professional practice ability is confirmed according to specialty norm and social needs.

1) The design of the practice ability training goal based on social needs

The total goal setting of training in computer application talents must meet the needs of the society [4]. Through the investigation to the employing unit, a variety of professional ability which should be set up and classified in the different positions of employment. Thus a number of professional categories are formed. Each category contains several abilities such as information management and network category. Information management category contains the 
ability of designing database system, using database system, achieving information extraction, selecting the database products, configuring database products, managing database, database user training and support ability [5]. And network category contains the ability of abstracting generalization problem, using the knowledge to analyze and solve problems, developing software based on network, networking and innovating [6]. So a clear goal is formed in course offered, content setting and assessment methods according to above abilities. The ability oriented education has distinct characteristics. That is the basis of teaching aim which is how to make the students have the ability to engage in a certain occupation. So the target is very specific [7].

2) The design of the practice ability training goal based on professional foundation

The combination of professional norms, applicationoriented talents should have basic professional practice ability, such as operating system management function simulation ability, optimization ability etc.

3) The design of the practice ability training goal based on professional practice

Determine the frontiers of computer development with the practice ability, such as the realization of mobile computing system capacity, development business solution capability etc.

4) The design of the practice ability training goal based on humanist literacy

Have the team cooperation ability, independent learning ability [8]; In addition, applied talent should have a certain sense of innovation that requires training students' thinking ability.

\section{B. Determine the train objective of practice teaching ability}

If the college has the software engineering and computer science and technology specialty, the ability target of specialty foundation and position in the above general objective are divided into the sub target group of the professional ability of software engineering and computer science and technology. Such, the ability target of each professional is clear.

\section{Rationally decompose every target into each of practical curriculum}

The sub target group of professional practice ability and the target of humanistic culture are decomposed into each practical curriculum. It makes each practical teaching target of the course can meet the needs of the society and be scientific. At the same time, practice course system is not scattered. But through the ability of the main line, it promotes the integration between practice courses.

\section{1) Course experiment and Practice}

The teaching target for training is divided into the ability of course. It includes course experiment and practice. The aim of the experiment is to strengthen the student's knowledge and understanding, culture the students' basic professional skills.
2) Small integrated experimental curriculum and comprehensive experimental courses

Improve the comprehensive ability of students to fuse multiple points, the ability of practice for design.

3) Graduation practice and graduation design

During the process of training applied talents, practice teaching is very important. Construct characteristic training practice base, realize the function are effective to achieve the training objectives of talent. Combining the characteristics of computer science speciality, by programming and construction of inside-school practice bases, the implementation of practice teaching improved the ability of practice and engineering quality of students.

\section{SPECIFIC IMPLEMENTATION}

Reform of one of the most important aspect is to strengthen the integrated computer professionals, the cultivation of innovative capabilities. Taking "ability training" as the core, reforming on the basis of the teaching content, teaching methods, teaching means and examination methods and construct "practice teaching system based on ability training".

\section{A. Practice of teaching content based on ability training}

The experiment teaching's design is important regarding the practical strong curriculum, experiment course content construction immediately affect student ability.

- These courses can be linked through capacity and combination ability. It can break through the barriers between curriculums, eliminate the duplication of knowledge courses, optimize the course content and construct the curriculum content system based on ability training. The teaching content of every course are subject to the overall goals in personnel training.

- The formation of modular curriculum structure. Through analyzing the problems encountered during constructing computer laboratories in colleges and universities, the author put forward a new scheme that is called "core\& modularized experiments area\& software platform". The establishment of the curriculum system fully reflects the ability as the core, which is characterized by project and task driven. Teaching project module is determined. And then curriculum module project is transformed. Such as: a curriculum module is formed through related curriculum. Teaching is charged with one or two teachers. For example: C language program design, $\mathrm{C}++$ program design, data structure experiment can be integrated. Teachers can join each other in the design of experiments.

- The proportion of comprehensive experimental project should be gradually increased in experiment courses.

- Experimental design should follow the principle of gradual, professional norms and the mainstream of social demand in the course of practice, professional practice and graduation practice. 


\section{B. Teaching method based on ability training}

In the independent colleges, the current teaching methods can not adapt well to cultivate applied talents. It is mainly reflected in the following aspects:

- Teaching emphasis on imparting knowledge, ability light.

- The cramming method of teaching is the main way.

- Independent college students are lack of learning initiative. If classroom teaching is solely relied for the computer professional, the practical ability of the students will not have greatly improved.

In order to solve the above problem, the following solutions are put forward:

- Use the teaching method of case teaching, heuristic, project driven etc.

- According to the aforementioned segmentation to practice ability, the imparting of knowledge is changed. And the ability to organize teaching is converted.

- Establish open experimental teaching mechanism. The computer labs are important places for teachingpractice in college and universities.

\section{Teaching means based on ability training}

\section{1) Establish rich library of course resources}

Students can choose amount of experimental projects such as verification, synthesis, design and innovation which establish in each course.

\section{2) Establish open practice teaching platform}

Through this platform, information of practice teaching include the process management of experiment course, graduation practice, graduation design. But is engaged in the computer teaching the teacher may borrow this without doubt to obtain the greatest income. Diversified evaluation mechanism

3) Establish curriculum evaluation mode based on different categories

Curriculum evaluation is to examine the students to grasp the situation of the curriculum knowledge. Examination is the main way of the traditional assessment methods. Assessment methods which are used paper-based test will get better results for theory course. But it is not applicable for highly practical computer science curriculums which pay attention to the actual operation skill. So assessment methods such as closed book exam, open book exam, major operation and small paper should be used according to the characteristics and the teaching objectives of different courses. In the examination content, it should be gradually from the content of assessment into ability assessment.

4) Establish curriculum assessment mechanism base on various levels and targets

According to the different professional direction, the personnel training goal is decomposed into several sub goals. The specific practice course and practice setting is concrete embodiment in each semester according to the distribution level progressive principle in the 8 semester. Various levels and targets curriculum evaluation mechanism is formed. 4 years total programming of computer professional students is set. The index is decomposed into the various practice course and teaching. As a specific quantitative indicators practice teaching quality, at the same time, normative, integrity and other qualitative index code quality and documentation, curriculum evaluation mechanism is formed which combines the qualitative index with quantitative index.

\section{Actively promote the students' science and technology innovation,competition and other activities}

The student extracurricular study extensive learning can be further guided through extending the practical teaching activities to extra-curricular. The main form includes: establishing students' innovative laboratory, promoting the students' practical ability and autonomous learning ability through participating in the actual project, organizing students to participate in the ACM program design contest and mathematical modeling contest, establishing the science club, interest group organization, guiding the students to carry out entrepreneurial activities.

\section{CONCLUSION}

In this paper, practice ability training target system is proposed which is combined with social demand. Various ability training targets in above system are decomposed into each practice course in order to determine ability training targets of each practice course. The teaching content of practice course is set based on ability training target. Innovation based on practice teaching method of ability training, teaching means and assessment methods is explored. The students' society oriented practical ability, autonomous learning ability and learning interest, the practice of teacher's ability of applying for social demand are improved through relying on the teacher's scientific research projects and undergraduate innovative experiment project .

\section{ACKNOWLEDGMENT}

This work has been funded by the project supported by teaching research fund of hubei provincial education department [2011463]. The authors gratefully acknowledge members of the project team for help.

\section{REFERENCES}

[1] $\mathrm{Yu}$ Bo,Qin Ye-mei, “A Pattern for Training Students' Innovative Ability of Computer Science in Independent College," In: Proceedings of the 2nd International Conference on ETCS, 2010, pp. $752-755$.

[2] Duanyang Zhao,Qingxiang Xu,Wuheng Zuo ,"The Research and Practice of Computer Teaching atIndependent Colleges for Students at Different Levels," In: Proceedings of the International Conference on ICIE, 2009, pp. 20 - 23.

[3] Yan Yang,Rong Li,Junmin Ye,"Professional Ability Training and Evaluation for Normal Undergraduates Majoring in Computer Science," In: Proceedings of the 4th International Symposium on ITME, 2011, pp. 527 - 531

[4] Quan-Jun Zheng, You-Rong Xiao,Xue Gong "'Research on quality guarantee system of practical teaching in higher vocational colleges," In: Proceedings of the International Conference on ICEIT, 2010, pp. $266-263$. 
[5] Hanxiao Shi ,"A novel computer-technology-based practical teaching for students of E-commerce specialty," In: Proceedings of the 5th International Conference on ICCSE, 2010, pp. 1531 - 1534.

[6] Liu Yan-heng,Mei Fang,Kang Hui ,"Research and reform on computer network practical teaching," In: Proceedings of the International Symposium on ITME, 2008, pp. 420 - 423.
[7] Zhang Ping,Han Lin "Research on the construction of practical teaching system for computer majors," In: Proceedings of the 6th International Conference on ICCSE, 2011, pp. 769 - 771.

[8] Chang-you Guo "Exploration and Research on Practical Teaching Mode in the Construction of Computer Professional Course Group," In: Proceedings of the 2nd International Conference on ETCS, 2010, pp. 565 - 567. 